\title{
Organização do serviço e análise de redes sociais: estudo de caso na Vigilância em Saúde Ambiental
}

\section{1 Carina Rodrigues Garcia Lino, 2 Márcia Gomide I}

Resumo: Discute-se a relação entre as redes sociais em ambientes de trabalho e sua influência na organização do serviço. Como cenário, investigouse o contexto da Vigilância em Saúde de Populações Expostas a Substâncias Químicas (VIGISOLO), um subsistema da Vigilância em Saúde Ambiental (VSA). Essa escolha visou aproveitar o momento propício à incorporação de ajustes pelo qual passa a VSA. Para a construção das redes sociais, levantaram-se dados secundários sobre o subsistema; realizaram-se observações da dinâmica de trabalho, entrevistas e questionários on line. Os dados facultaram identificar as cadeias de relações entre os profissionais e construir os sociogramas representativos dessas ligaçôes para as esferas federal, estadual e municipal de governo. A integração dos sociogramas permitiu a construção da rede coletiva. Esta, constituída por 25 atores, caracterizou-se por apresentar poucas ligações interpessoais dentre as possíveis, indicando ser uma rede de baixa densidade. Destacaram-se as ligaçōes informais e em pequenos grupos, normalmente associadas à confiança entre os indivíduos. Essa característica dificultou o repasse de informações, comprometendo alguns processos de trabalho. A possibilidade de identificar fragilidades na rotina operacional faz da Análise de Redes Sociais uma abordagem metodológica capaz de contribuir com o serviço, prestando-se como ferramenta balizadora para a gestão.

\author{
1 Instituto de Estudos em \\ Saúde Coletiva. Universidade \\ Federal do Rio de Janeiro. Rio \\ de Janeiro-RJ, Brasil. Endereço \\ eletrônico: carinarglino@ \\ gmail.com \\ ${ }^{2}$ Instituto de Estudos em \\ Saúde Coletiva. Universidade \\ Federal do Rio de Janeiro. Rio \\ de Janeiro-RJ, Brasil. Endereço \\ eletrônico: gomide@iesc.ufrj.br
}


A Vigilância em Saúde Ambiental visa ao conhecimento, detecção e prevenção de mudanças nos fatores determinantes e condicionantes do meio ambiente que interfiram na saúde humana (BRASIL, 2002). Ela é operada pelo Sistema Nacional de Vigilância Ambiental (SNVA), compreendendo um conjunto articulado de instituições do setor público em suas três instâncias governamentais e do setor privado, integrados ao Sistema Único de Saúde (SUS). Essa organização o torna um complexo circuito de coletividades e individualidades, requerendo integração de profissionais com distintas competências e exigindo arranjos político-executivos entre as três esferas hierárquicas de governo. Semelhante estrutura necessita, portanto, de um sistema de informação ágil e capaz de englobar características tão especiais (CÂMARA; TAMBELLINI, 2003), cuja operacionalização e fortalecimento têm sido o desafio da Vigilância em Saúde Ambiental. E como ainda está em consolidação, há receptividade a mudanças, tornando esse sistema propício à incorporação de ajustes no processo.

$\mathrm{Na}$ perspectiva de contribuir com tais ajustes, definiu-se como cenário de partida um de seus subsistemas, cujas peculiaridades englobassem o máximo de facetas deste complexo circuito hierárquico e heterogêneo de informações. Nesta concepção, investigou-se o contexto organizacional da Vigilância em Saúde de Populaçôes Expostas a Áreas Contaminadas (VIGISOLO).

O VIGISOLO é descentralizado e está implantado em todos os estados e em grande parte dos municípios do Brasil (PISAST, 2012). Tem como objetivo desenvolver estratégias de vigilância em saúde, adotando medidas de promoção, prevenção e atenção integral à saúde das populações, identificando os grupos susceptíveis aos fatores de risco e exposição a áreas contaminadas (PISAST, 2012). Este complexo cenário exibe inúmeras dificuldades, envolvendo a operacionalização da vigilância da saúde nas diferentes instâncias de governo (VIANA; MACHADO, 2009).

Para a operacionalização de serviços, é essencial que haja investimento nas articulações entre as instâncias e setores, que possuem, por sua vez, autonomia, governança e papéis bem delimitados (BRASIL, 1990). A existência de diálogo é primordial para que alcancem as metas estabelecidas no setor. No caso em questão, identificar tais diálogos proporciona informação a respeito das práticas desenvolvidas pelos profissionais na operacionalização do serviço. Deste diálogo entre os diversos profissionais, nas distintas instâncias e com diferentes atuaçôes 
e funções, é que emergem as redes de relações (DEGENNE; FORSÉ, 2004), formando as redes sociais.

Redes sociais podem ser consideradas como um conjunto de "nós" conectados socialmente entre si, por ligaçōes entre pessoas (MARIN; WELLMAN, 2009). A complexidade de comportamentos e personalidades destas pessoas, somada à tentativa de estabelecerem trocas ou favores (FREEMAN, 1992), age na motivação para o estabelecimento de ligações (VARANDA, 2007), que através de diferentes mecanismos de comunicação favorecem a transmissão de informações (DEGENNE; FORSÉ, 2004) no contexto organizacional.

A associação entre características de uma rede e sua influência nos sistemas pode ser observada a partir de sua estrutura (MARSDEN, 2005), basicamente dividida em três tipos: (a) a rede individual, (b) a rede coletiva e (c) a cadeia relacional. A rede individual, ou personal network (MARIN; HAMPTON, 2007), ou ego-rede (egocentric network) contempla as relações diretas ou indiretas de um ator social (MARSDEN, 2005). A rede completa ou coletiva (whole network) é composta por ligações entre atores, pertencentes a determinado grupo social delimitado (MARSDEN, 1990; 2005). Apesar de ser artificial, esta delimitação é condição necessária para a investigação (VARANDA, 2007). E, por fim, a cadeia relacional é composta por uma sequência simples e direta de pessoas, na qual cada uma conhece a próxima formando uma cadeia, onde as relações dos atores são analisadas a partir de seus intermediários (DEGENNE; FORSÉ, 2004). Ou seja, "quem conhece quem, que conhece quem".

Entretanto, seja qual for o tipo de rede, analisa-se o conjunto das relações que as compõem, seus padrōes e efeitos sobre as instituições (FONTES, 2012), sobre suas normatizações e seu funcionamento, dentre outros. Este conjunto compõe as propriedades estruturais da rede, que são elementos descritores. Informam sobre suas características constitutivas, tais como tipos de centralidade, tipos de ligação e número de pessoas que se conhecem.

A centralidade pode ser: (a) centralidade de grau, onde se identifica a quantidade de ligaçõos que um ator com os outros da rede (McCARTY, 2010); (b) centralidade de intermediação, que referencia a capacidade de um ator ser intermediário, ou seja, em mediar fluxos de informação ou recursos entre outros atores (DORNELAS, 2012); e (c) centralidade de proximidade, com a qual é possível medir a capacidade de independência do controle de um ator 
pelos outros da rede (McCARTY, 2010), ou seja, quantas pessoas existem entre ele o seu interlocutor.

A densidade expressa o número de relações possíveis entre as pessoas de uma rede em comparação com o número de relações existentes. As relações são caracterizadas por sua intensidade e impessoalidade e conhecidos como "tipos de ligaçōes", que podem ser formais ou informais e fortes ou frágeis (GRANOVETTER, 1973).

E sendo a rede social dinâmica, por estar sujeita às variações relacionais entre atores, é analisada a partir do enfraquecimento ou fortalecimento de ligações, em função de novos vínculos estabelecidos, oferecendo possibilidades de compreender momentos diferenciados de um mesmo sistema organizacional e verificar sua influência na operacionalidade do serviço (GOMIDE; GROSSETTI, 2010). Assim, a análise de redes sociais pode ser utilizada para identificar dificuldades de comunicação entre atores vinculados a uma organização formal (MANGIA; MURAMOTO, 2005). A informação produzida poderá ser aplicada pela gestão com a finalidade de ajustar os procedimentos inerentes ao serviço.

E pautado nesse cenário, onde planejar e monitorar as ações de vigilância requer comunicação constante entre as instâncias e as áreas do saber (BRASIL, 2005), somadas às questões organizacionais e atribuições da VSA (BRASIL, 1988) perante a demanda de recorrentes situações de risco ambiental, urge contribuir com seu fortalecimento. Desta forma, tem-se como objetivo descrever e analisar a rede coletiva referente aos atores envolvidos na gestão, decisão e operacionalização de açôes relacionadas ao VIGISOLO nas três esferas governamentais.

\section{Procedimentos metodológicos}

A pesquisa em análise de redes sociais pode ter caráter quantitativo, quando investiga redes de grande porte, envolvendo dezenas ou centenas de informantes. Ou pode ter caráter qualitativo, quando seu cenário de investigação inclui poucos informantes, como na investigação em questão.

$\mathrm{O}$ público-alvo desta pesquisa foi composto pelas equipes pertencentes ao VIGISOLO, de um estado e de um município brasileiros e na Federação, escolhidos por se destacarem positivamente na perspectiva das ações em saúde 
ambiental e pela diversidade de profissionais envolvidos, imprimindo mais possibilidades de bons resultados à pesquisa. O público-alvo foi delimitado intencionalmente, condição básica para a realização de um estudo de análise de redes (MARSDEN, 2005; VARANDA, 2007; FONTES, 2012).

A coleta de dados em análise de redes sociais é classicamente baseada na utilização de técnicas complementares: entrevistas, observação sistemática no local (GOODE; HATT, 1977; RAMPAZZO, 2005), aplicação de questionários e levantamento de dados secundários. As observações sistemáticas ocorreram antes e ao longo do período de entrevistas, já que objetivavam o conhecimento do local, da equipe das rotinas e dos documentos. Esta técnica permite a "exploração" do cenário em investigação e auxílio à comparação entre o verbalizado e o informado com as práticas cotidianas, seguindo um roteiro (MINAYO, 2010; BERG, 2001). Todos os setores foram visitados e as entrevistas agendadas previamente.

As entrevistas semiestruturadas tiveram como objetivo identificar os percursos pessoais e relações estabelecidas. Dos 25 profissionais identificados, foram entrevistados 19 e os demais não quiseram participar. As entrevistas foram iniciadas com quatro "informantes de partida", definidos por exercerem cargo de chefia, sendo formalmente responsáveis nas três instâncias governamentais. A esses informantes foi solicitado que citassem nomes de profissionais que integrassem sua equipe de trabalho, que constituíram os próximos entrevistados da equipe. Para cada um dos informantes, foi reconstruída a história das relações interpessoais (MARSDEN, 2005). Após a realização das entrevistas, foi enviado a todos os profissionais um questionário on line, cujo objetivo foi detalhar as rotinas de trabalho e formas de comunicação (memorandos, celular, e-mail, outras tecnologias, almoços...) empregadas para solucionar problemas ou seguir o fluxo diário do serviço, sem haver identificação do informante. Dos 25, 17 deram retorno.

Os dados secundários foram obtidos em bancos de dados (Sistema de Informaçōes de Vigilância em Saúde de Populações Expostas a Solo Contaminado - SISSOLO) e a partir de documentos normativos (Instrução Normativa 01/2005; VIII Inventário Nacional de Vigilância em Saúde, 2011; decretos e portarias municipais e estaduais), os quais tiveram a função de auxiliar na descrição do contexto operacional e funcional do sistema, bem como de descrições relativas aos recursos humanos. 
Com base na ligação entre os atores e suas histórias nas unidades (MARIN; WELLMAN, 2010), foram elaboradas as redes de cada uma das três instâncias. Em seguida, a partir da conexão entre as relações interpessoais (MARSDEN, 1987; 2005; GROSSETTI, 2005) nas diferentes instâncias, foi construída a rede coletiva do VIGISOLO, composta pelos 25 profissionais e representada no sociograma da figura 1 . O sociograma é a representação esquemática visual da rede de relaçoos, expressando as características estruturais da "teia" de relacionamentos, base das análises em redes sociais.

$\mathrm{Na}$ análise da rede, foram considerados aspectos da dimensão relacional, da dimensão estrutural e da configuração, tais como densidade da rede; centralidade entre os atores, "pontos de intersecçōes" entre as redes, consideradas como pontos de transmissão de informações ou recursos entre grupos, visando à identificação de fluxos de comunicação. Outros pontos analisados foram os conteúdos transacionais ,como relações de confiança e cooperação. ${ }^{1}$

\section{Resultados e discussão}

\section{O contexto}

Segundo organogramas funcionais, dos 25 profissionais participantes, 18 estavam oficialmente vinculados à execução de atribuições descritas pelo VIGISOLO. A gerência municipal à qual está vinculado este subsistema utiliza um modelo de operacionalização capaz de absorver os instrumentos "clássicos" das vigilâncias sanitária e epidemiológica. Uma subgerência foi criada para administrar ações referentes às áreas técnicas: água, ar, solo e desastres. Nesta, as atribuiçôes estão distribuídas entre cinco profissionais. Há uma rotatividade na função de substituto do subgerente, acordada entre os profissionais como estratégia nos afastamentos oficiais. Os atores se comunicam através de reuniōes ordinárias, e-mail, e por celulares. As ligações formais prevalecem, mas as relações informais de amizade são fortes e influenciam diretamente no processo de trabalho da equipe.

Já os profissionais da instância estadual que se localizam no setor da Vigilância Sanitária (VS) atuam de forma descentralizada, em concordância quanto a metodologia e forma de executar o trabalho. São três os atores responsáveis pelas 
ações, e a figura do coordenador é reconhecida e aceita no âmbito federal. O

mecanismo de comunicação mais utilizado entre eles é o telefone fixo profissional e em seguida, o e-mail.

O setor da Vigilância Epidemiológica (VE) também executa, na instância estadual, atribuiçôes do VIGISOLO. Este é composto por quatro atores, que não são necessariamente considerados como referência técnica formal pelos demais integrantes da equipe. Alguns profissionais que atuam na Vigilância Epidemiológica possuem dupla vinculação, pertencendo tanto ao estado quanto ao município, na Vigilância em Saúde Ambiental. Esses dois atores se relacionam com os outros profissionais da VE estadual somente quando solicitados. No município, estão um pouco periféricos. O mecanismo de comunicação mais utilizado entre eles é o telefone fixo profissional e em seguida, o $e$-mail. Tanto os atores da VS quanto os da VE consideram-se independentes e atuam de forma autônoma, mas têm ligação direta com o nível federal.

$\mathrm{Na}$ instância federal, o setor responsável pelo VIGISOLO é composto por dois profissionais, fora a coordenação geral, contabilizando três profissionais, conforme informação obtida. A rotina de trabalho é bem estabelecida, permitindolhes atuar com número reduzido de colaboradores. O coordenador está no cargo há algum tempo. No entanto, há alta rotatividade entre os profissionais técnicos contratados, vinculados à execução nas diferentes frentes de trabalho da Saúde Ambiental. O mecanismo de comunicação mais utilizado entre os profissionais é o celular e em seguida, o e-mail.

\section{Descrição e análise das redes}

Os tipos de ligações identificadas na rede coletiva, conforme o sociograma S4 (figura 1), caracterizaram-se como ligações fortes, frágeis, formais e informais, além de relações rompidas. A ligação formal é definida como um laço profissional estabelecido por comunicações realizadas pelos profissionais apenas quando necessário à conduta organizacional. O laço formal forte é verificado quando a ligação se estabelece há algum tempo e os atores se falam com mais frequência, além do estritamente necessário ao cotidiano das atividades profissionais, sem contudo extrapolar as atividades de trabalho. Laços fortes podem dar origem a grupos fechados denominados cliques. 
Cliques podem ser fechadas ou abertas, exercendo papel negativo ou positivo, respectivamente. Somente na rede S2B não foram assinaladas. O laço formal pode ser frágil, ou extremamente frágil. Neste caso, a comunicação é aquém do necessário, comprometendo o repasse de informações entre os atores; as ligações rompidas, caracterizadas pela existência de ruptura de uma ligação do passado, verificada pela ausência de contatos no presente; e por fim, (e) os laços informais caracterizados como laços de amizade fortalecidos por contatos frequentes além dos espaços de trabalho formalmente definidos.

A rede coletiva (visualizada no sociograma $S 4$ - figura 1) representa a conexão entre as redes das diferentes instâncias (sociogramas S1, S2A/S2B e S3). Se houvesse interação entre todos esses atores na rede, deveria haver 600 ligações entre eles. No entanto, foram identificadas apenas 118 ligaçōes, correspondendo a 0,196 ou $19,6 \%$ de contatos. Este baixo número de ligaçôes existentes, quando comparado ao número máximo possível, indica que não há muita comunicação entre os profissionais. Trata-se, portanto, de uma rede com baixa densidade.

A densidade da rede é calculada a partir da divisão do número de relações existentes ( $\mathrm{x}$ ) pelo número de relações possíveis ( $\mathrm{n} \times \mathrm{n}-1)$. O resultado é multiplicado por 100 , obtendo-se o percentual que varia de zero a $100 \%$. Este último é o valor máximo de densidade que uma rede pode alcançar, expressando que todos os atores se relacionam entre si. Ou seja, esse percentual indica o aproveitamento que se tem de relações da rede (VELÁZQUEZ; AGUILAR, 2005). Sendo assim, a rede coletiva representada no sociograma da figura 1 , com menos da metade das ligações possíveis, tem baixa densidade.

O sociograma S1 (figura 1) exibe as interações entre profissionais na instância municipal (representados por círculos). São sete atores, sendo 56 as ligações possíveis e 40 as ligações observadas; 32 são ligações formais, duas dessas fortes, quatro ligaçōes formais extremamente frágeis e quatro ligações informais fortes. É possível observar um trio fortalecido e uma dupla de atores com laço informal forte. Não são identificados atores periféricos ou isolados. A densidade desta sub-rede é de 0,72 , o que significa um aproveitamento de $72 \%$ do potencial de relaçôes da rede. Nesta, observa-se o maior número de ligações com as outras 
sub-redes em comparação com os outros sociogramas, mas essas ligações externas

ao S1 estão concentradas em um só ator. Uma das ligações formais extremamente frágeis é estabelecida por um dos atores mais centrais das redes. O outro ator central não apresenta ligações rompidas ou formais muito frágeis com os atores do S1; no entanto, apresenta ligações rompidas com atores visualizados em outros sociogramas (S2A e S2B).

O sociograma S2A representa o setor central responsável pelas ações na Vigilância Sanitária (VS) na instância estadual (ilustrado por triângulos). Está composto por três profissionais ligados por laços fortes com densidade de $100 \%$, quatro ligaçōes formais e duas informais. O fluxo de informaçōes transcorre de forma a atender às demandas entre eles. Todavia, há ligações rompidas e relaçôes formais extremamente frágeis concernentes aos atores das redes S2B e S1. A relação com o ator periférico, que deveria mediar as ações oficiais entre S2A e S2B, é formal extremamente frágil. Entretanto, existe uma ligação formal e forte com um dos atores da instância federal (S3).

O sociograma S2B representa a rede de profissionais da Vigilância Epidemiológica (VE) na esfera estadual (figurados por triângulos). Quatro atores dos sete que compõem a rede são formalmente responsáveis pelas ações. Das 42 ligações possíveis nesta sub-rede, 24 foram identificadas, resultando em uma densidade de 57\%. A prevalência das ligações é de caráter formal. Há ligações rompidas e relações formais extremamente frágeis com atores das sub-redes, S2A e S1, respectivamente.

O sociograma S3 representa a rede do setor do VIGISOLO na instância federal e está ilustrado por retângulos. Três das seis pessoas são formalmente encarregadas da rotina. São 30 as ligações possíveis e 20 as ligaçôes existentes, o que confere à rede a densidade de $67 \%$. As relações informais prevalecem em detrimento das formais, entre os atores mais centrais da rede, diferentemente das ligações que compõem as demais instâncias. Parte dessa equipe, que gerencia o componente VIGISOLO nesta instância, está atuando há mais de cinco anos. Com as redes (S1) e (S2A) existem ligações formais fortes. 


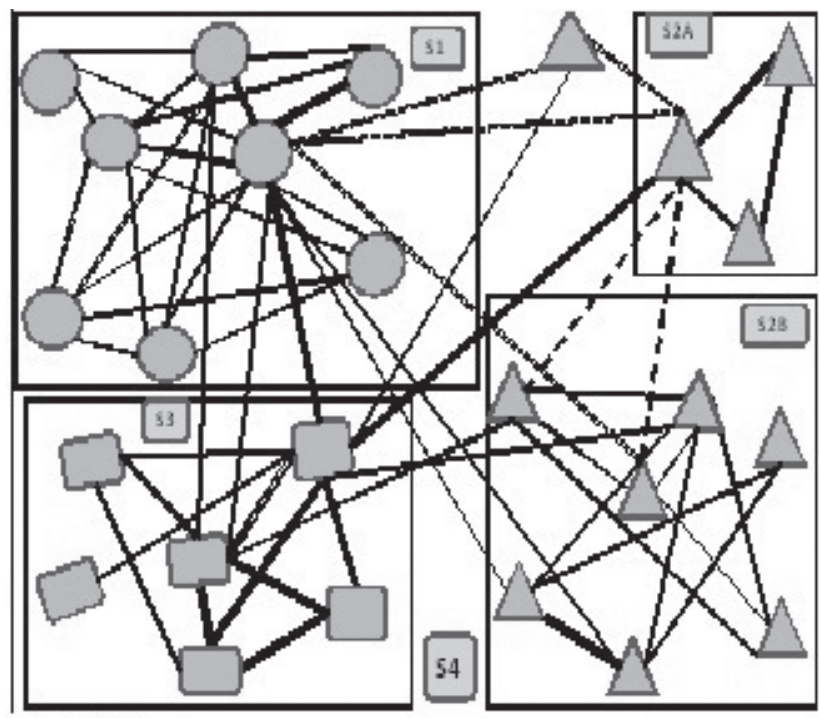

\section{Legenda:}

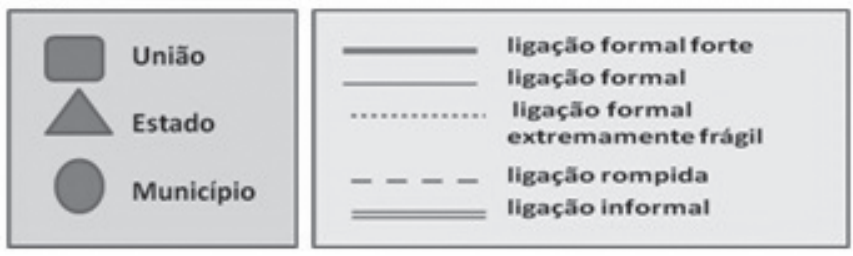

A análise dos sociogramas considerou as medidas estruturais "clássicas" (McCARTY, 2010), priorizando as de densidade, centralidade e cliques. A análise de redes possibilita observar que as relações interpessoais variam em quantidade (densidade da rede), intensidade (laços mais ou menos fortes) e em centralidade (indivíduo com mais ligações na rede). Estas características em conjunto indicam como os atores se organizam informalmente para solucionar problemas de rotina e tomar decisões independentemente da organização oficial do sistema.

Assim, é possível observar quão influentes são as redes de relações informais no dia a dia do trabalho e quão importantes são os aspectos da dimensão relacional (confiança e cooperação), dimensão estrutural (força dos laços) e das medidas estruturais da rede (centralidade), principalmente quando analisados em seu conjunto (RÉGIS; BASTOS; DIAS, 2007). 


\section{Densidade}

Se a densidade igual a $1.0 \mathrm{em}$ uma rede equivale dizer que se trata de uma rede densa onde todos se relacionam com todos, utilizando $100 \%$ do seu potencial; uma densidade zero equivale à ausência de ligaçōes, ninguém se conhece, não há relações estabelecidas (McCARTY, 2010). Uma rede densa cria oportunidades para a existência de muitos subgrupos nos quais todos se conhecem entre si. No caso em estudo, apesar da existência de ligações fortes e de centralidade, a densidade da rede coletiva (conjunto de todas as redes - S4) é baixa, indicando pouco aproveitamento inter-redes do potencial das ligaçóes para troca de recursos e de capital social.

Os recursos, empregados de forma adequada pelos atores, podem auxiliar no alcance de objetivos. Assim, uma rede com maior densidade tende a apresentar melhor fluxo de capital social, que gerado nas relações (PORTUGAL, 2006) pode ser utilizado pela estrutura social em prol de seu próprio benefício. A rede representada no sociograma S1 (esfera municipal) exemplifica esta situação. Há poucas ligações com as demais redes, indicando possíveis perdas de oportunidade no intercâmbio de capital social, ou de recursos.

A rede representada pelo sociograma S2A (esfera estadual, VS) tem densidade interna alta e na rede S2B (esfera estadual, VE), a densidade é média. Entretanto, há poucas ligaçõos entre ambas, indicando possíveis oportunidades perdidas de trocas de recursos. Pode-se concluir que ambas são capazes de operar bem internamente, mas não necessariamente entre elas. Já a densidade da rede na esfera federal (S3) é alta, sugerindo bom desempenho interno. O líder tem ligações com os representantes das demais instâncias, garantindo contatos e repasses de recursos, tanto quanto de capital social a partir de ligaçôes fortes, que geram confiança, compensando de alguma forma as poucas ligações entre as esferas estaduais e a municipal.

\section{A confiança, a cooperação e as cliques}

Como toda relação informal tem como base a confiança, esta é fator determinante para a estruturação do sistema organizacional (VALENTIM; KRUEL, 2007). Entretanto, as relações estabelecidas entre atores que compõem uma organização também apresentam como elemento essencial a "confiança organizacional” (LANE, 1998). A cooperação é um efeito direto associado aos 
laços de confiança (VALENTIM; KRUEL, 2007) e influencia positivamente a rotina de trabalho. Sendo assim, a confiança, sob o ponto de vista da formação das ligações nas redes informais está relacionada à amizade (GIDDENS, 1991) e é conquistada com o tempo de relacionamento existente entre os atores e com a integridade daqueles que compõem a rede (GRANOVETTER, 1973), como verificado no sociograma S3.

Nessa conjuntura, a manutenção das relações colaborativas passa a ser um projeto em que os atores são envolvidos e integrados (CUNHA; MELO, 2006). Entretanto, se a confiança e a cooperação se restringem a um pequeno grupo, indicado pela formação de pequenos grupos fechados (cliques), como é observado no sociograma S4, o efeito pode ser negativo. Cliques resultam do estabelecimento de fortes relações informais, ao longo do tempo, caracterizadas por sua coesão e alto nível de confiança com mais ou menos abertura para contatos (VARANDA, 2007).

A intensidade e a tipologia das ligações e a formação de subgrupos ou cliques (VARANDA, 2007) entres os atores puderam ser observadas. Se por um lado, cliques fechadas são importantes para o controle da disseminação de informaçōes de caráter mais confidencial (RÉGIS; BASTOS; DIAS, 2007), por outro, podem influenciar negativamente a dinâmica do grupo no que diz respeito ao fluxo dos recursos, atuando como um filtro da informação com caráter seletivo (HANNEMANN, 2000; MARTELETO, 2001; BITTENCOURT; NETO, 2009; PORTUGAL, 2006). As três cliques identificadas, uma em cada instância de governo, com exceção da rede representada no sociograma S2B, exerceram papéis diversos em função dos atores centrais e com centralidade no processo de trabalho.

A centralidade se caracteriza pelo "nó" ou ator, do qual parte a maioria das relações (DEGENNE; FORSÉ, 2004). Quando um ator exerce a função de chefia, pertence a uma clique e ainda tem centralidade, diz-se que este possui elevado capital social (PORTUGAL, 2006) pois agrega maior poder e controle, influenciando consideravelmente as tomadas de decisão (RÉGIS; BASTOS; DIAS, 2007). Para conquistar a centralidade, é preciso interação, coesão, confiança e relações de amizade, que extrapolam os limites profissionais, facilitando o repasse de recursos, favorecendo a comunicação e reforçando suas 
ligações (HANNEMANN, 2000). Entretanto, nesta análise, a situação mostrouse um pouco mais complexa.

No sociograma S2A nota-se uma clique que, apesar de verificada sua capacidade executiva interna, estabelece pouca interlocução com atores de outras sub-redes, que não a observada com o a rede S3. Trata-se de uma clique "periférica", que por tal característica pode vir a comprometer a troca de recursos, já que a interação com outras instâncias seria condição necessária para promover ações coletivas de melhorias das condições de vida e saúde da população (HANNEMANN, 2000; LANDIM, 2010).

$\mathrm{O}$ efeito negativo que cliques muito fechadas podem exercer sobre os demais atores da rede refere-se também ao surgimento de sentimentos como inveja, ciúme pelo não pertencimento à clique, por não gozar de certos benefícios que o grupo possui, por não possuir privilégios ou por não deter um número maior de informações a respeito do processo de trabalho. Estes atores em cliques são polarizadores de acesso à informação e a privilégios (PORTUGAL, 2007), exercendo comumente a posição hierárquica maior no organograma funcional (PORTUGAL, 2006).

As cliques fechadas normalmente fortalecem os atores envolvidos, porém, neste contexto, desfavoreceram o repasse da informação, onde filtros foram estabelecidos entre os atores dessas cliques, privilegiando uns em detrimento de outros, no acesso à informação, influenciando diretamente a dinâmica de trabalho dessas equipes em investigação. Ao mesmo tempo, onde não foram identificadas relações de confiança e cooperação entre atores, identificaram-se ligações formais extremamente frágeis, caracterizadas por ruídos, que penalizavam as negociações, dificultando a interação entre os atores.

A capacidade de integração entre os atores resulta em cooperação. Esta é um processo interativo onde atores podem traçar coletivamente uma estratégia ou desenvolver uma solução em que haja investimento de ambas as partes (GRAY; WOOD, 1991). Elase estabelece por haver confiança entre as pessoas e normalmente está associada à credibilidade em relação aos resultados obtidos (GIDDENS, 1991). Como tais características podem ser cruciais para o funcionamento de um subsistema como o VIGISOLO, estas deveriam ser potencializadas entre as três instâncias, pois o panorama inter-redes nas esferas estadual e municipal é de relativa 
fragilidade. Tal circunstância é incompatível com a proposta de descentralização, mas de certa forma é sobrepujada pelas ligações fortes da rede S3. O investimento em formas de comunicação que compensem laços fragilizados seria uma opção em favor da ininterrupção do fluxo de informação.

\section{O fluxo de informação, comunicação e os tipos de laços}

Uma vez que a rede social se estabelece espontaneamente, sua dinâmica pode influenciar diversamente o processo de trabalho, inclusive contornando a configuração de cargos instituída (OLIVER et al., 2012). O fluxo da informação existente entre as redes $S 1$ e $S 3$, notadamente a clique, está associada a ligações informais entres seus atores, demonstrando tal dinâmica. A passagem da informação no meio organizacional via laços informais tende a chegar a seu destino com maior velocidade (RÉGIS; BASTOS; DIAS, 2007).

Já os laços formais frágeis estão em destaque entre as ligações observadas no sociograma S4 e, apesar de frágeis, também são mecanismos de acesso à informação (GRANOVETTER, 1973), já que procedem da formalidade. Além disso, na esfera pública os laços frágeis têm como característica a mobilização de recursos formando estoques de capital social compartilhados pela comunidade política (FONTES, 2012). O ideal é que exista uma mistura de laços fortes e fracos (LEMIEUX, 2001) e uma harmonia entre relações de amizade e puramente profissionais, para que haja um bom capital social, sob os diferentes conteúdos transacionais circulantes na rede, como o conhecimento técnico, a confiança e a cooperação (RÉGIS; BASTOS; DIAS, 2007).

Nessa rede, a circulação ou compartilhamento de tais conteúdos se faz por meios tecnológicos tanto quanto contatos diretos, existindo relação próxima entre a tecnologia empregada e tipo de laço. Os meios de comunicação mais utilizados entre os atores das redes apresentadas no sociograma S1 e S2A são o telefone profissional fixo e e-mail. $\mathrm{Na}$ rede $\mathrm{S} 2 \mathrm{~B}$, o celular e o telefone profissional fixo são os principais canais de comunicação. Os contatos mais formais são efetuados por telefone profissional fixo e/ou e-mail. Já os atores que utilizam o celular como canal de comunicação mais frequente possuem ligações fortes de caráter informal.

A recorrência de uso do celular e a existência de laços informais também se verificam entre atores que ocupam cargos de gerenciamento, que demandam resoluçōes imediatas. Além do celular, as redes sociais na internet também são 
um canal de comunicação explorado pelos atores que possuem maior grau de intimidade. $\mathrm{O}$ e-mail é a forma de comunicação adotada entre os profissionais principalmente para "formalizar" contatos ou solicitaçoes, documentando-os, o que até pouco tempo era feito por "ofícios" e memorandos.

Desta forma, os mecanismos propulsores dos fluxos de informação resultam dos tipos de vínculos estabelecidos na rede social da organização e da posição em que estão na rede. Esses mecanismos auxiliaram a superar a complexidade administrativa de seu sistema operacional. Os profissionais com maior abrangência de ligações, notadamente os pertencentes à esfera federal, souberam utilizar oportunidades de comunicação na rede. Aproveitando-se delas, podem estar em posições mais favoráveis, onde o acesso a recursos como conhecimento e informação é associado à detenção de poder (HANNEMAN, 2000).

\section{Centralidade e liderança}

Enquanto a densidade é a medida de quantidade dos laços na rede, a centralidade é uma medida de coesão (McCARTY, 2010). Quando um indivíduo tem centralidade, possui mais ligações que os demais integrantes, o que lhe confere maior acesso a informaçôes e recursos de diversas ordens (GRANOVETTER, 1973). A centralidade viabiliza o repasse de recursos, favorecendo uma melhor gerência.

Os atores com maior centralidade associada aos fluxos de comunicação construídos (FREEMAN; DANCHING, 1997; FREEMAN, 1979) e ao repasse de recursos não materiais (PORTUGAL, 2006) são aptos a assumir posições hierárquicas mais altas no organograma funcional, como observado nos atores mais centrais dos sociogramas S1 e S3. Sobretudo o ator do sociograma S3 exercendo posição de liderança, contando com o controle do fluxo da informação no contexto organizacional (HARRIS; CLEMENT, 2007), com conhecimento técnico, e consequentemente, com poder (PORTUGAL, 2007), teve papel agregador em prol dos objetivos sobre o andamento das ações do VIGISOLO.

Esse ator faz o papel de intermediador, que associado a uma posição estratégica na rede torna-se fator positivo, favorecendo alguns fluxos de informação entre as sub-redes. Por outro lado, alguns atores que ocupam cargos de coordenação e deveriam possuir centralidade não a têm. Nestas sub-redes são os atores politicamente atuantes que possuem a centralidade. E nesse contexto 
de contradiçōes, determinado ator em S1, cuja centralidade é alta, mas sem ter função formal, apesar de importante para a solução imediata de problemas, acaba por anular a autonomia e o poder de tomada de decisão do responsável formal. Esse tipo de antagonismo fragiliza o processo de trabalho.

\section{A organização e os "efeitos" da rede}

$\mathrm{O}$ contexto investigado representa o recorte de uma estrutura complexa, composta de "múltiplos sistemas de saúde", onde as demandas e necessidades tomam diferentes formas. Assim, a organização política em um município e em um estado impera pela cultura de prioridades de cada local, pelos aspectos definidos por cada gestor sobre como organizar a oferta de serviços a sua população. $\mathrm{Na}$ vigilância em saúde, diferentes formatos organizativos objetivam desenvolver as competências e atribuições definidas em lei (BRASIL, 1990) e por isso passa a ser vital elaborar um sistema de comunicação que se encarregue de promover trocas e retroalimentações entre os "atores-pessoas" e "atores-organizações".

Redes sociais são estruturas invisíveis (GROSSETTI; BES, 2001) e poderosas inerentes à vida e às organizações. A análise destas se torna uma ferramenta crucial ao auxiliar o aperfeiçoamento dos processos de trabalho, notadamente neste caso, dadas suas especificidades, que exigem, das três esferas de governo, procedimentos capazes de tornar mais ágil o sistema de informação/comunicação. A partir da rede social (S4), é possível verificar como a rede interfere nesta dinâmica e o quanto ela pode contribuir para o sucesso ou insucesso de uma tarefa. Muitas das articulaçõos profissionais ocorrem graças aos laços informais. As ligações informais tiveram papel importante, mas que não chegou a remediar certas ausências de ligações em alguns setores. Essa situação comprometeu os fluxos de informação e, consequentemente, a interação preconizada pelo modelo de saúde (BRASIL, 1990). Isto porque o sucesso dos sistemas formais e organizacionais está na dependência dos fluxos de informação e de comunicação (RÉGIS; BASTOS; DIAS, 2007). Além disso, quanto mais informais são as ligações entre os atores, mais independentes são esses atores de sua organização formal, e mais independentes passam a ser de seus processos de trabalho. O contrário também pode ser considerado, pois quanto mais formais são as ligações entre os atores, mais dependentes são do sistema. 
O "equilíbrio" desses dois processos é a chave para um sistema resolutivo. Encontrar esse "equilíbrio" é um processo complexo, pois as redes estão em contínua movimentação e a saída de um elemento ou a entrada de outro influencia nas configurações reticulares e na movimentação do conteúdo transacional. Como encontrá-lo não é garantia de sucesso, pois este depende de dimensões opostas: uma formal e controlável e outra informal e incontrolável, é importante que a rede seja densa. Em redes mais densas, aumentam-se as chances de haver equilíbrio entre os procedimentos normativos e as soluçôes paliativas à organização do serviço.

Considerando-se a diversidade de profissionais, as atividades do VIGISOLO e a busca por tal equilíbrio, alguns ajustes poderiam ser benéficos. Estes incluiriam o planejamento de espaços virtuais de comunicação em redes, capazes de absorver diferentes fluxos e conteúdos de informação aberta a todos os envolvidos. O uso destes espaços virtuais coletivos, os quais são alimentados por "postagens" contínuas, poderia ser uma estratégia para compensar as baixas densidades identificadas em alguns setores e incorporar as cliques ao conjunto.

Como já apontam muitos cientistas políticos e administradores públicos, o uso das redes se faz urgente (DENIS, 2010). Conhecer os padrões e a dinâmica das relações pode permitir o fortalecimento das ações, por indicar com mais precisão onde e o que necessita de ajuste. Para cada fragilidade identificada na rede deve ser planejada uma estratégia específica que seja compensatória e agregadora. $\mathrm{O}$ conjunto dessas soluções será o elo entre as redes, suscitando o diálogo e tornando o sistema mais ágil, condição primordial para o alcance das metas. Alcançar as metas, para o setor VIGISOLO, pressupóe ser capaz de programar e operacionalizar ações de vigilância, promoção, prevenção e atenção integral às populações expostas a solos contaminados, sempre em sincronia.

A identificação de profissionais isolados no sistema ou em função discordante ao cargo, tanto quanto o uso de subterfúgios - mesmo que eficazes - ao cumprimento de tarefas, indica falta de sincronia e sugere uma revisão de organograma. Esta visaria otimizar potencialidades, facilitar tarefas e aproximar pessoas, aumentando as chances de confiança e cooperação. Um reajuste de organograma com tal perspectiva poderia ser uma solução complementar para compensar as fragilidades da rede do setor VIGISOLO. 
Como operacionalizar o complexo sistema da Vigilância Ambiental é o grande desafio, a identificação e superação destes pontos fragilizados no setor VIGISOLO pode oferecer subsídios para elaboração de estratégias no âmbito geral da Vigilância Ambiental, uma vez que se trata de uma área considerada multiprofissional, mobilizadora e integradora (BRASIL, 1990). Avaliar regularmente o contexto de intercâmbio de recursos na organização do serviço seria um modo inovador de operacionalização do sistema. Como consequência, o VIGISOLO seria mais resolutivo e ainda mais apto a garantir a integralidade da atenção, prevenção e promoção da saúde da população.

\section{Conclusão}

Sem a existência de um fluxo ininterrupto de repasse de recursos e de capital social, é difícil tornar ágil um sistema. O setor VIGISOLO em análise, apesar de ser considerado um dos mais completos, apresenta algumas fragilidades neste fluxo. Estas estão relacionadas ao processo de operacionalização de atividades cotidianas, bem como aos padrões e a dinâmica das relaçôes suscetíveis à falta de comunicação entre as pessoas. Os pontos frágeis identificados foram: (a) os atores das sub-redes se comunicam pouco, como indicam as baixas densidades. (b) as baixas densidades influenciam diretamente na dinâmica de intercâmbio, resultando em oportunidades perdidas de repasse de recursos; (c) algumas cliques observadas na rede coletiva são fechadas, o que interfere na interação e promove o represamento de recursos.

A oferta de espaço de comunicação virtual coletivo e a reestruturação do organograma poderiam ser benéficas a este subsistema, compensando a baixa densidade de ligaçôes e integrando os indivíduos de cliques à rede coletiva. Contudo, foi possível identificar um efeito positivo da cooperação e confiança nas ligações informais e sua influência no sistema, principalmente relacionado à rede S3, da esfera federal, proporcionando a resolutividade existente no serviço.

Como a estrutura do serviço administrativo é a base para um bom desempenho e qualidade das atividades, ou seja, para a capacidade de implementar açôes direcionadas as populações, o aperfeiçoamento na operacionalização do sistema acaba por possibilitar a melhoria da atenção integral a população.

Enfim, a aplicação da análise de redes sociais permitiu a identificação do encadeamento dos fluxos de informação e comunicação estabelecidos entre os 
profissionais do subsistema VIGISOLO. A visualização de tais cadeias relacionais

mostrou-se como ferramenta sinalizadora para a gestão. Os gestores ou planejadores podem utilizar estas sinalizações, como subsídio à proposição de estratégias que estimulem configurações de redes mais densas na organização do serviço. ${ }^{2}$

\section{Referências}

BERG, B. L. Qualitative research methods for the social sciences. New York: Pearson, 2001.

BITTENCOURT, O. N. da S.; NETO, F. J. K. Rede social no sistema de saúde: um estudo das relaçôes interorganizacionais em unidades de serviços de HIV/AIDS. Revista de Administração Contemporânea, v. 13, edição especial, p. 87-104, 2009.

BLIN, T. Ressources, stratégies et régulation d'un espace d'action colletive: la cas des «refugiés» de Saint-Ambroise. L'Année Sociologique, v. 55, n. 1, p. 171-196, 2005.

BRASIL. Constituição da República Federativa do Brasil: promulgada em 5 de outubro de 1988. Brasília, DF: Senado, 1988.

BRASIL. Ministério da Saúde. Lei no 8080, de 19 de setembro de 1990. Disponível em: <https://www.planalto.gov.br/ccivil_03/leis/18080.htm>. Acesso em: 21 fev 2009.

BRASIL. Ministério da Saúde. Vigilância em Saúde Ambiental. Brasília: Fundação Nacional de Saúde, out. 2002.

BRASIL. Ministério da Saúde. Plano Nacional de Monitoramento e Avaliação. Programa Nacional de DST/Aids. Brasília: Ministério da Saúde. Secretaria de Vigilância de Saúde, 2005. BURT, R. S. Structural holes versus network closure as social capital. In: LIN, N.; COOK, K. S.; BURT, R. S. (Ed.). Social Capital: theory and research. London: Aldine Transaction, 2001. CÂMARA, V. M.; TAMBELLINI, A. M. T. Consideraçôes sobre o uso da epidemiologia nos estudos em saúde ambiental. Rev. Bras. Epidemiol., v. 6, n. 2, p. 95-104, 2003.

CUNHA,C.R.C.;MELO, M.C.O.L.A confiança nos relacionamentosinterorganizacionais: o campo da biotecnologia em análise. ERA, v. 5, n. 2, art. 18. jul.-dez, 2006.

DEGENNE, A.; FORSÉ, M. Les réseaux sociaux. Paris: Armand Colin, 2004.

DENIS, J. L. Institucionalização da avaliação na administração pública. Rev. Bras. Saúde Matern. Infant., v. 10, supl. 1., p. 5229-5237, 2010.

DORNELAS, M. A. Redes de sociabilidade, governança e participação: aspectos da relação Estado e sociedade civil no Programa de Saúde da Família. Os casos de Recife e Porto Alegre. 2012. 212 f. Tese (Doutorado em Sociologia) - Pós-Graduação em Sociologia. Universidade Federal de Pernambuco, Recife, 2012.

FREEMAN, L. C. Centrality in social networks: Conceptual clarification. Social Networks, v. 1, p. 215-239, 1979. 
FREEMAN, L. C. Social Networks and the Structure Experiment. In: FREEMAN, L. C.; WHITE, D. R; ROMNEY, A. K. Research methods in social network analysis. California: Transaction, 1992.

FREEMAN L. C.; DANCHING, R. An international comparative study of interpersonal behavior and role relationships. L’Année Sociologique, v. 47, n. 1, p. 89-115, 1997.

FONTES, B. Interfaces do combate/prevenção de Aids e tuberculose em Recife. In: FONTES, B.; MARTINS, P. H. (Org.). Redes, práticas associativas e gestão pública. Recife: Ed Universitária da UFPE, 2006. p. 75-112.

FONTES, B. A. S. Redes locais e poder local. Recife: Ed. Universitária da UFPE, 2012.

GIDDENS, A. As consequências da modernidade. São. Paulo: UNESP, 1991.

GOMIDE, M.; GROSSETTI, M. Rede social e desempenho de programas de saúde: uma proposta investigativa. Physis: Revista de Saúde Coletiva. Rio de Janeiro, v. 20, n. 3, p. 873-896, 2010.

GOODE, W. J.; HATT, P. K. Observação. In: GOODE, W. J.; HATT, P. K. Métodos em Pesquisa Social. São Paulo: Companhia Editora Nacional, 1977.

GRANOVETTER, M. The strength of weak ties. The American Journal of Sociology, v. 78, p. 1360-1380, 1973.

GRAY, B.; WOOD, J. Collaborative alliances: moving from practice to theory. Applied Behavioral Science, v. 27, n. 1-2, March/June, 1991.

GROSSETTI, M.; BES, M-P. Encastrements et découplages dans les relations scienceindustrie. Revue Française de Sociologie. Paris, v. 42, n. 2, p. 327-355, 2001.

GROSSETTI, M. Where do social relations come from? A study of personal networks in the Toulouse area of France. Social Networks, v. 27, p. 289-300, 2005.

HANNEMANN, R. A. Introducción a los métodos del análisis de redes sociales. Departamento de Sociología de la Universidad de California Riverside, 2000. Disponível em: < revistaredes.rediris.es/webredes>. Acesso em: 10 dez. 2012.

HARRIS, J. K. H.; CLEMENT, B. Social network analysis of Missouri's emergency planners. Public Health Reports, v. 122, 488-498, July-Aug. 2007.

KUIPERS, K. J. Formal and informal networks in the workplace. 1999. 117f. Tese (Doutorado em Administração) - Stanford University, Stanford, CA, EUA, 1999.

LANDIM, F. L. P. et al . Análise das redes interpessoais: aplicação na realidade de uma equipe de enfermagem atuando em unidade de hematologia. Saude soc., São Paulo, v. 19, n. 4, p. 828-827, dez. 2010.

LANE, C. Introduction: theories and issues in study of trust. In: LANE, C.; BACHMANN, R. (Ed.). Trust within and between organizations. Oxford: Oxford University Press, 1998. p. 2-15. 
LEMIEUX, V. Social capital in situation of co-operation and conflict. ISUMA, v. 2, n. 1, s/p, 2001. Disponível em: <http://socialcapital.spno.ca/bibliography.pdf.>

LINO, C. R. G.; ÁSMUS, C. I. R. F.; GOMIDE, M. Gestão da Vigilância em Saúde Ambiental: um modelo de aplicação da metodologia de análise de redes sociais. Interface. Trabalho em análise, s/d.

LINO, C. R. G.; GOMIDE, M. Análise de redes sociais na avaliação do programa de controle de hanseníase em um município do interior do Brasil. Cad. Saúde Colet., Rio de Janeiro, v. 20, n. 1, p. 32-40, 2012.

MANGIA, E. F.; MURAMOTO, M. T. O estudo de redes sociais: apontamentos teóricos e contribuições para o campo da saúde. Rev. Ter. Ocup. Univ. São Paulo, São Paulo, v. 16, n. 1, p. 22-30, jan-abr., 2005.

MARIN, A.; HAMPTON, K. N. Simplifying the personal network name generator. Alternatives to traditional multiple and single name generators. Field Methods, v. 19, n. 2, p. 163-193, 2007.

MARSDEN, P. V. Core discussion networks of Americans. American Sociological Review, v. 52, n. 1, p. 122-131, Feb., 1987.

MARSDEN, P. V. Network data and measurement. Annual Review of Sociology, v. 16, p. 435-463, 1990.

MARSDEN, P. V. Recent developments in network measurement. In: CARRINGTON, P. J.; SCOTT, J.; WASSERMAN S. (Ed.). Models and methods in social network analysis. Cambridge: Cambridge University Press, 2005 (Structural Analysis in the Social Sciences, n. 28).

MARTELETO, R. Análise de Redes Sociais: aplicação nos estudos de transferência da informação. Cien. Inf. Brasília, v. 30, n. 1, p. 71-81, jan-abr. 2001.

MCCARTY, C. La estructura en las redes personales. REDES, v. 19, n. 11, Diciembre 2010. MINAYO, M. C. S. O desafio do conhecimento: pesquisa qualitativa em saúde. São Paulo: Hucitec, 2010.

NEUVILLE, J-P. La tentation oportuniste. Rev. Francaise de Sociologie, Paris, v. 39, n. 1, p. 71-103, 1998.

OLIVER, K. et al. The human factor: re-organizations in public health policy. Health Policy, v. 106, p. 97-103, 2012.

PISAST. VIII Inventário Nacional de Vigilância em Saúde Ambiental. Referência: Brasil, ano-base 2011, 2012.

PORTUGAL, S. Quanto vale o capital social? O papel das redes informais na provisão de recursos. In: FONTES, B.; MARTINS, P. H. (Org.). Redes, práticas associativas e gestão pública. Recife: Ed Universitária UFPE, 2006. p. 51-74. 
PORTUGAL, S. Contributos para uma discussão do conceito de rede na teoria sociológica. Oficina do CES, n. 271, março 2007.

RAMPAZZO, L. Metodologia Científica. São Paulo: Loyola, 2005.

RÉGIS, H. P.; BASTOS, A. V. B.; DIAS, S. M. R. C. Redes sociais informais: análise das redes de amizade, de informação e de confiança em incubadoras de base tecnológica no Recife. Rev Psic Org e Trabalho, v. 7, n. 1, p. 31-56, 2007.

VAITSMAN, J. Cultura de organizações públicas de saúde - notas sobre a construção de um objeto. Cad. Saúde Pública, Rio de Janeiro, v. 16, n. 3, p. 847-850, jul-set, 2000.

VALENTIM, I. V. L.; KRUEL, A. J. A importância da confiança interpessoal para a consolidação do Programa de Saúde da Família. Ciênc. saúde coletiva, Rio de Janeiro, v. 12, n. 3, jun. 2007.

VARANDA, M. P. Acção colectiva entre pequenos empresários: uma análise de redes sociais. Análise Social, v. XLII, n. 182, p. 207-230, 2007.

VELÁZZUEZ, A. A. O.; AGUILAR, N. G. Manual introductorio al análisis de redes sociales. Chapingo: Universidad Autónoma del Estado de México y Universidad Autónoma, 2005.

VIANA, A. L. A.; MACHADO, C. V. Descentralização e coordenação federativa: a experiência brasileira na saúde. Ciênc. saúde coletiva, Rio de Janeiro, v. 14, n. 3, p. 807-817, jun. 2009.

\section{Notas}

${ }^{1} \mathrm{O}$ artigo é resultado de tese de doutorado, defendida no Instituto de Estudos em Saúde Coletiva da UFRJ em abril de 2013. Não há conflito de interesses e não houve financiamento. A pesquisa foi realizada nos padrões éticos exigidos pela Comissão Nacional de Ética em Pesquisa, sob o parecer $\mathrm{n}^{\circ}$ 68/2011 e processo no 22/2011, de 06/07/2011.

${ }^{2}$ C.R.G. Lino participou da elaboração da proposta de pesquisa, coleta dos dados, análise e construção do texto. M. Gomide elaborou, analisou e participou de todas as etapas de construção e organização do artigo, tendo orientado tese de doutorado que o originou. 
Organizational network analysis: a case study in Environmental Health Surveillance

There is some discussion on the relationship between social networks in work environments and their influence on service organization. We investigated the context of the Health Surveillance of Populations Exposed to Chemicals (VIGISOLO), a subsystem of Environmental Health Surveillance (VSA). This choice aimed to seize the right moment for incorporating adjustments experienced by VSA. For the construction of social networks, secondary data on the subsystem were collected; observations of the dynamics of work, interviews and questionnaires online were conducted. Data provided identification of chains of relationships between professionals and built representative sociograms of these links to federal, state and municipal government levels. The integration of sociograms allowed the construction of the collective network. This, consisting of 25 actors, characterized by having few interpersonal connections among the possible ones, indicating a low density network. Informal links stood out in small groups, usually associated with trust between individuals. This feature made it difficult to transfer information, compromising some work processes. The ability to identify weaknesses in the operational routine makes Social Network Analysis a methodological approach able to contribute to the service, lending itself as tool for management.

> Key words: environmental health; social network analysis; health surveillance. 